\title{
Poesía escénica. El arte del actor en el teatro épico-dialéctico ${ }^{1}$
}

\section{Likana harawi. Likachikukaap artin maanaku-tiklaa likanapaaćhu}

\section{Kaninatsaengaro ogonijantiro: ora ikanti ira osiakagantaneri - kengagansi}

Recepción: 02 febrero 2020

Corregido: 16 junio 2020

Aprobación: 01 marzo 2021

Jorge Prado Zavala

Nacionalidad: mexicana

Instituto de Educación Media Superior de la Ciudad de México (IEMS)

Correo: jaime.prado@iems.edu.mx,jpradoz@yahoo.com.mx

Publons Web of Science Researcher ID: C-6350-2018

ORCID: https://orcid.org/0000-0002-0169-7255

\section{Resumen}

Este reporte de caso monográfico busca dar a conocer la poética teatral de Bertholt Brecht a quienes no la conocen, y ofrecer otras perspectivas a quienes ya se le han acercado. A partir de Massimo Castri, Bertholt Brecht, Luis de Tavira y la experiencia de algunos intérpretes teatrales, se analizan las características del perfil actoral del teatro épico-dialéctico y, bajo esa óptica, el trabajo particular de la Compañía Nacional de Teatro (México) en su puesta en escena de El círculo de cal. Es así como el trabajo persigue explicar esta teatralidad a quienes no están familiarizados con el teatro de Brecht y también abrir otras perspectivas a sus conocedores.

\section{Palabras clave:}

Actor, Brecht, Teatro épico.

\section{Lisichiku limaykuna:}

Likachiku Likana, Brecht, Maanaku likapaana.

\section{Nibarintsipage}

Osiakagantaneri, Brecht, osiakagananaronte-

katsimaro

\section{Datos del autor}

Actor, director, docente e investigador en artes escénicas, lengua y literatura. Doctor en Humanidades (Teoría Literaria) por la Unidad Iztapalapa de la Universidad Autónoma Metropolitana UAM-I). Maestro en Literatura Comparada por la Universidad Nacional Autónoma de México (UNAM). Miembro de la Asociación Mexicana de Investigación Teatral (AMIT) y coordinador de su Seminario de Actoralidades de la Escena Contemporánea (SAEC). Enlace-coordinador del Equipo Interdisciplinario de Investigaciones Escénicas (EIIE) del Instituto de Educación Media Superior de la Ciudad de México (IEMS).

1 Todas las fotografías del artículo fueron tomadas y autorizadas por Sergio Carreón Ireta (CíaNT). 


\title{
Scenic Poetry. The Art of The Actor in The Epic-Dialectic Theater
}

\begin{abstract}
This monographic case report seeks to make Bertholt Brecht's theatrical poetics known to those who do not know, and offer other perspectives to those who have already approached. Based on Massimo Castri, Bertholt Brecht, Luis de Tavira and the experience of some theatrical interpreters, the characteristics of the acting profile of epic-dialectical theater are analyzed and, from that perspective, the particular work of the National Theater Company (Mexico) in his staging of The Circle of Lime. This is how the work seeks to explain this theatricality to those who are not familiar with Brecht's theater and also to open other perspectives to its connoisseurs.
\end{abstract}

Keywords

\section{Religious representation in the oral tradition of the province of Pasco}

Resumo

Este reporte de corte monográfico visa conhecer a poética teatral de Bertholt Brecht a quem ainda não a conhece e oferecer outras perspectivas a quem já se aproximou dela. A partir de Massimo Castri, Bertholt Brecht, Luis de Tavira e da experiência de alguns intérpretes teatrais, são analisadas as características do perfil atoral do teatro épico-dialético e, sob essa ótica, o trabalho particular da Companhia Nacional de Teatro (México) da sua posta em cena da obra, O círculo de cal. Dessa forma o trabalho busca explicar essa teatralidade para quem não está familiriarizado com o teatro de Brecht e também abrir outras perspectivas para seus conhecedores.
Actor, Brecht, Epic Theater.

Palavras-chave:

Ator, Brecht, teatro épico. 
A Óscar Narváez, el actor que no buscaba al teatro pero que fue encontrado por él.

\section{Introducción: un espectáculo con "historia"}

El círculo de tiza caucasiano (Der kaukasische Kreidekreis) es una obra teatral que escribió Bertholt Brecht entre 1944 y 1945 en Santa Mónica, Estados Unidos. Se estrenó el 4 de mayo de 1948 en Northfield (Minnesota) en la sala del Nourse Little Theatre, Carleton College. Está inspirado en el cuento El círculo de tiza, del chino Li Xingdao, que evoca el relato bíblico de un famoso juicio celebrado por el Rey Salomón. Hasta el 9 de noviembre de 1954 pudo presentarse por fin en Berlín, en la entonces República Democrática Alemana, apenas dos años antes del fallecimiento de Brecht (14 de agosto de 1956), siendo así su último montaje como director, su "Canto del Cisne".

El círculo de cal es una versión de Luis de Tavira y Eduardo Weiss a El círculo de tiza caucasiano. Varios son los factores que apartan a esta obra y a su puesta en escena de las coordenadas de una teatralidad convencional. Nos hacemos una pregunta: ¿"no convencional” podría todavía significar "revolucionaria" en el siglo XXI?

El círculo de tiza caucasiano presenta la historia de Grusha, quien forma parte de la servidumbre del gobernador Gueorgui. Un ejército enemigo está por llegar a la ciudad para linchar a Gueorgui y a toda su familia, por lo cual el gobernador ordena huir, pero en los preparativos su esposa Natela deja atrás a su propio hijo recién nacido. Grusha cae en la tentación de recoger al niño bajo su protección, arriesgando su propia vida, y es entonces perseguida sin tregua. Grusha bautiza al niño con el nombre de Misha, y así se convierte, por amor, en su madre.

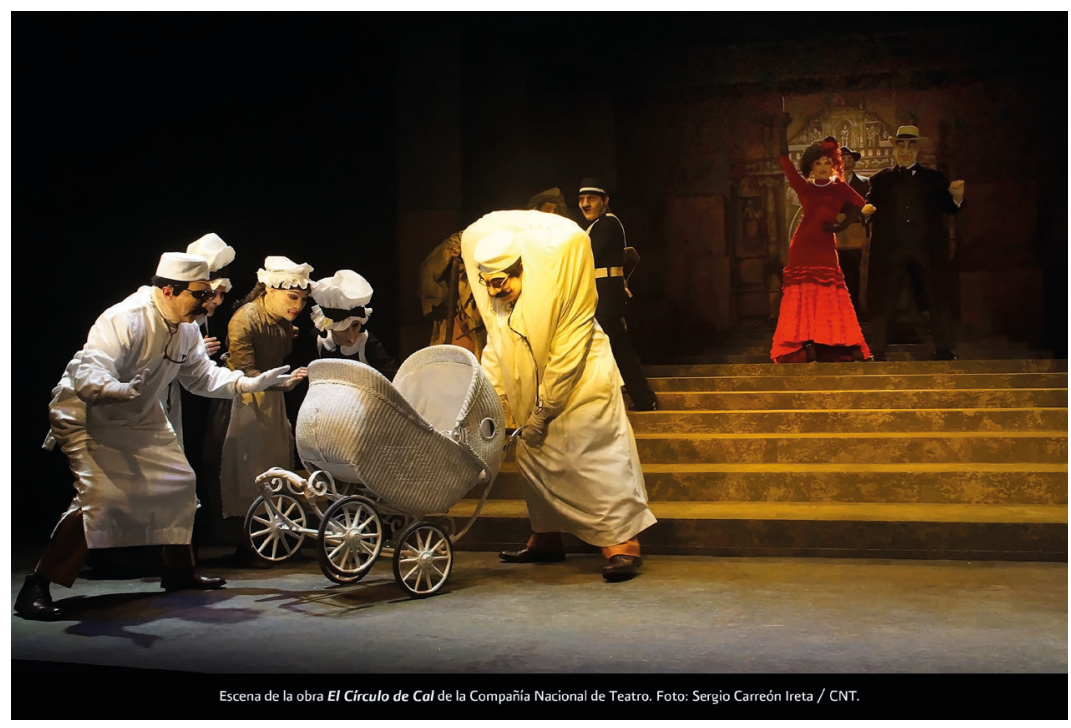

Es en el año de 2013 cuando el entonces director artístico de la Compañía Nacional de Teatro (CíaNT), Luis Fernando de Tavira Noriega, decide montar en México esta obra paradigmática del Teatro Épico. El teatro épico no es un modelo nuevo para el creador mexicano que ya, desde 1974, explorase las peligrosas fronteras entre el teatro y la política con Esperando al 
zurdo de Clifford Odets, y que después de estudiar con Beno Besson en el Berliner Ensemble fundara el Taller de Teatro Épico (1976) y dirigiera La gran revolución de Jaime Augusto Shelley (1977), La honesta persona de Sechuán de Brecht (1978), La sombra del caudillo de Martín Luis Guzmán, adaptada con Arturo Beristáin y Joaquín Garrido (1980), luego la mítica Martirio de Morelos de Vicente Leñero (1983), hasta Santa Juana de los mataderos de Brecht (2002), entendiendo que, para hacer una reflexión sobre la verdad, la historia y la justicia, hacía falta una estrategia teatral que, además de belleza, tuviera verdad e inteligencia, esto es, un teatro capaz de mostrar que la realidad es transformable: "En la medida en que pudiéramos pasar de la denuncia de las desdichas que padece la mayoría a la de señalar las condiciones de posibilidad para aniquilar sus causas, ese es para mí el teatro más efectivo." (Luis de Tavira, entrevistado por Armando Ponce en Proceso. 19 de septiembre de 1981).

De manera independiente a dramaturgos, directores y a los propios actores, el teatro implica siempre un trabajo de equipo que no siempre es del todo reconocido por críticos y mucho menos por teóricos del teatro; si pretendemos hablar de transformación de la realidad desde el ejercicio comunitario del teatro, cabe entonces hacer explícitas las aportaciones de todo un equipo. Por eso, queremos hacer aquí un breve reconocimiento de ese trabajo, correspondiente a otra clase de actuación teatral: Habría que considerar que, si "actor" es "el que hace”, entonces con más razón en un contexto teórico cercano al socialismo, como lo es el Teatro Épico, el equipo de producción ameritaría ser considerado una especie actoral particular, la de los actores cuyo hacer se ubica detrás del escenario. De Tavira es reconocido por no escatimar recursos de producción para sus puestas en escena. A este respecto, la escenografía de Philippe Amand se basa en una escalinata capaz de significarse en múltiples espacios dramáticos: la alcaldía del gobernador Gueorgui, casas de pueblo y de campo, bosques, un juzgado, o el río caudaloso que se convierte en la catarata mortal donde sucede una de las más intensas escenas de la historia reciente del teatro mexicano, con la persecución de los soldados presionando a Grusha para cruzar un puente dañado, con tal de no entregarles al pequeño Misha para su ejecución. Citlalli Hueso y Glenys McQueen-Fuentes coordinaron la expresión corporal con vestuarios de Jerildy Bosch y máscaras (para todos los actores) de José Pineda. La música fue compuesta por Rafael Fuentes Orduña, arreglada por Alberto Rosas e interpretada en vivo por Edwin Tovar, Paul Conrad, Juan Carlos Pacheco y RAM. El encargado de mantener en forma la dirección escénica original de De Tavira fue Octavio Michel. En cada función el público fue personalmente atendido por los anfitriones Erzy Yoseff, Cecilia Merelo y/o César Carbajal. Hasta aquí hemos mencionado al equipo de producción, ahora hablaremos de los actores "dramáticos".

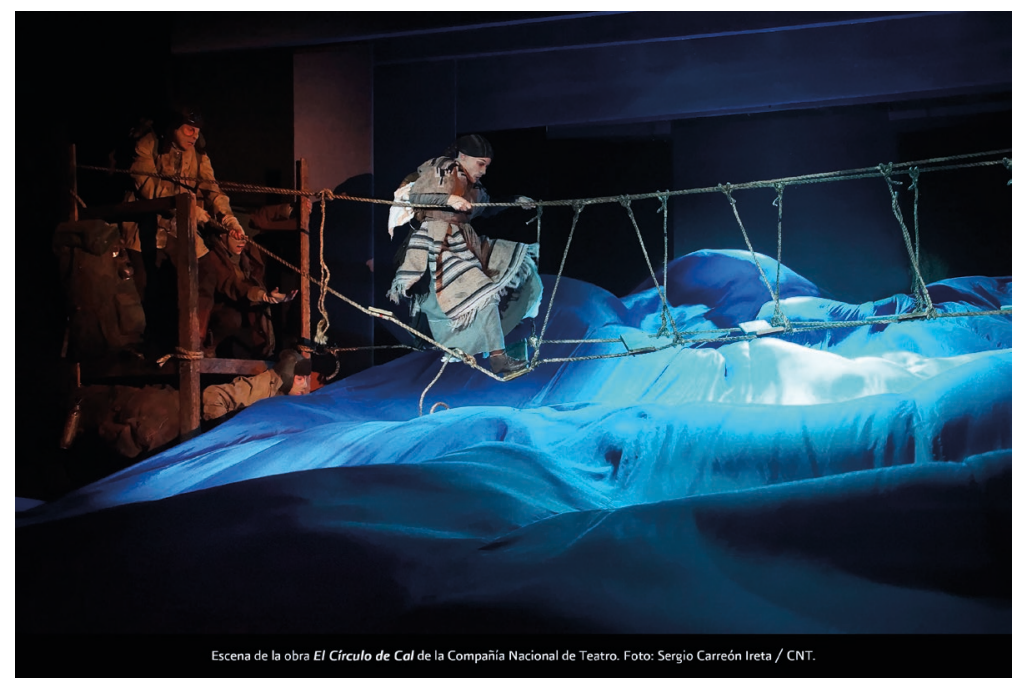


Volvamos, pues, a la noción ortodoxa del actor sobre la escena. El elenco de El círculo de cal ha sido una verdadera "Selección Nacional de Actores" para México, una veintena por noche, para 69 personajes. Entre 2013 y 2017 actuaron, en diferentes temporadas: Érika de la Llave (siempre en el entrañable papel de Grusha), Adrián Aguirre, Misha Arias de la Cantolla (quien se estrenó para la CíaNT como su personaje homónimo, Michel o Misha, en la obra), Enrique Arreola, Marta Aura, Eduardo Candás, Mariana Gajá, Marco A. García, Mariana Giménez, Héctor Holten, Luisa Huertas, Diego Jáuregui, Blanca Loaria, Tony Marcín, Rosenda Monteros, Laura Padilla, Roberto Soto (en el significativo rol del juez Azdak, entre otras caracterizaciones), Paulina Treviño, Rodrigo Vázquez, Andrés Weiss, Ana Ligia García, Pilar Padilla, Gabriela Núñez, Óscar Narváez, Emma Dib, Rocío Leal, Patricia Madrid, Carlos Orozco, Yulleni Pérez Vertti, Miguel Cooper, Ana Isabel Esqueira, Marco Antonio García, Olaff Herrera, Ana Paola Loaiza. Hasta aquí hemos nombrado a todos los ejecutantes concretos de la partitura brechtiana, los denominados "actores", en su definición convencional.

Una ambición recurrente entre los artistas escénicos es que su quehacer devenga en algún momento en un impacto social profundo, homologando entonces el trabajo del actor al de un agente cultural capaz de cambiar su entorno, su comunidad. Esta ambición coincide, por cierto, como en su momento veremos, con los objetivos políticos de Bertholt Brecht (creador comprometido con la izquierda).

En el siguiente apartado haremos un análisis elemental de la estructura dramática de esta obra, a partir de la teoría de los géneros dramáticos (atribuida en su forma más desarrollada a Luisa Josefina Hernández), para entender la base sobre la cual los actores podrán construir un espectáculo lo suficientemente significativo y conmovedor como para motivar a sus participantes, tanto en el escenario como en la sala de butacas, a buscar un cambio en sus propias personas, y, eventualmente, a transformar su mundo.

\section{Una estructura "didáctica"}

Repasando el hilo argumental, la obra El círculo de cal nos comparte la historia de la sirvienta Grusha Vajnazde que, en medio de una cruenta guerra, cede a la tentación de la bondad para salvar y hacerse cargo del bebé Michel (o, de cariño, Misha), hijo del despótico gobernador ("sanguijuela" lo denomina Brecht en su dramatis personae) Gueorgui Abashvili, arriesgando entonces su propia vida en un ingrato viaje por un mundo terrible carente de justicia.

Si, como nos afirman Luisa Josefina Hernández (en Alatorre y en Rivera) y Fernando Martínez Monroy (en su cátedra de teoría dramática), los géneros dramáticos son fórmulas probadas y bien estructuradas a partir de la trayectoria del protagonista para propiciar efectos precisos en el espectador, entonces, en El círculo, ¿a qué nos enfrentamos, si se supone que los creadores como Brecht aspiran a transformar al mundo?

Vale la pena discutir si un género dramático nos puede proponer factores ¿éticos, políticos, sociales, morales, económicos, culturales? suficientes como para transformar al mundo. Veamos. Por ejemplo, a pesar del estilo de puesta en escena, que en su arte visual caricaturesco nos recuerda una y otra vez que estamos viendo teatro y no un hecho real, El círculo de cal es más que una farsa, pues no sólo nos reímos histéricamente ante el horror y el absurdo de las situaciones, sino que también nos conmovemos hasta el llanto. Pero en este ejercicio de emociones moralizantes tampoco estamos ante un melodrama de "buenos" contra "malos", pues ni es "buena” Natela, la esposa del gobernador Gueorgui cuando reclama la recuperación de su 
hijo, ni tampoco son tan "malos" el corrupto juez Azdak, ni la "robachicos" Grusha. En una tragicomedia donde el personaje atravesase, como aparenta, un sinnúmero de obstáculos, desde la muerte inminente hasta el juicio final, se nos dejaría una reconfortante riqueza espiritual, sin embargo, aquí además se nos deja con abrumadoras dudas, sobre todo ¿de quién son los hijos? Las posibles respuestas apuntan a una enseñanza moral y social. Estamos pues ante una obra didáctica (el séptimo género en la teoría dramática de Luisa Josefina Hernández) cuyo propósito es más sutil pero más arriesgado, consistente en cuestionar nuestra noción de la justicia, pero intentándolo sin encontrar para ello una solución cómoda. Grusha, por ejemplo, antes de saber que rescatará al indefenso Michel, se compromete con el soldado Simón Jajava. El drama reproduce un texto que también se lee por separado en las antologías poéticas del autor.

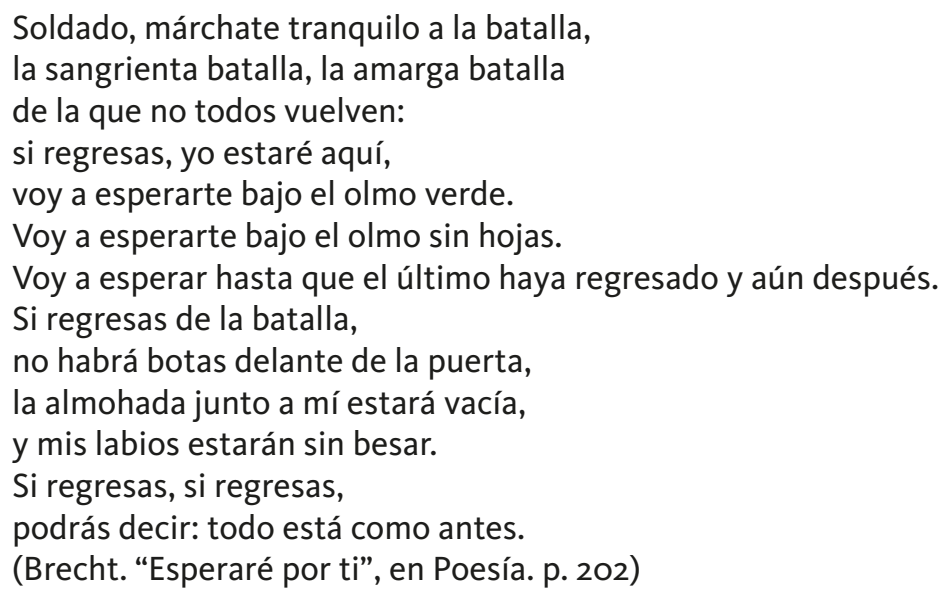

¿Cómo explicará Grusha a su prometido, si es que éste vuelve de la guerra, que ahora tiene un hijo que no es de él? El tema es, pues, político y social, y sorprendentemente ameno. Mucho ayuda que se apoye en una espectacularidad musical, no en el sentido de las comedias musicales o music halls más conocidos hoy, alegres y desenfadados, sino en aquel que abrevara del oscuro y pesimista cabaret de la entreguerra germana, mismo que Kurt Weill aprovechara para componer la música original de la Ópera de los tres centavos (Die Dreigroshenoper, 1928), y que se convirtiera en el ritmo escénico particular del Berliner Ensemble.

Fue el mismo Brecht quien comenzó a denominar a sus obras "piezas didácticas" cuando, entre 1928 y 1933, publicó varias de ellas, como la Pieza didáctica de Baden sobre el consentimiento, que acrecentaron su fama tanto en lo artístico como en lo político (primero anarquista y luego comunista). "El término obra didáctica refiere en nuestros días algo más que a un género dramático", nos dice Virgilio Ariel Rivera (La composición dramática, p. 137).

La función del género didáctico no es simplemente enseñar. [...] Se dirige ya al entendimiento, a un índice intelectual socialmente determinado, a la conveniencia de orden público, y a la razón desarrollada de la colectividad. [...] Equivale a un juicio público racional, lógico y metódico ante el cual los espectadores conformarían el jurado popular. (p.138)

El círculo de cal, de hecho, representa en su escena culminante un juicio (presidido por el juez interino Azdak) donde el público es co-partícipe (y donde se decidirá de quién es el niño que protege Grusha). El juicio tiene como acusada, pues, a Grusha, acusada de robachicos, o más bien, como sugiere el coro de la obra, por "caer en la tentación de la bondad." Se debate en consecuencia la tutela, o más explícitamente, la propiedad, del niño-objeto Michel. En esta 
obra de Brecht, el infante Michel no sólo es una alegoría del sentido profundo de la patria potestad (¿de quién son los hijos?), sino además de los derechos sobre la tierra y sobre cualquier otro patrimonio. Si los personajes no son tan simples, la historia lo es menos. ¿Cómo presentarla al espectador?

Para cumplir sus propósitos, [la obra didáctica] recurre a todos los temas, a todas las anécdotas y a todas las formas de conducta humanas; da cabida a todas las fórmulas, a todos los lineamientos de todos los géneros, especialmente a las de los otros dos considerados simples, la tragicomedia y el melodrama, y en casos esporádicos la tragedia, aunque, diferentemente a estos géneros, se desarrolla siempre en el realismo o en el expresionismo; la obra didáctica no es nunca romántica como la tragicomedia, ni sobria como la tragedia, ni pueril como el melodrama. (Rivera p. 139)

Ahora intentemos observar los que, según explica Ariel Rivera, siempre siguiendo la cátedra de Luisa Josefina Hernández, son los tres recursos teatrales más aprovechados por el género dramático didáctico, analizando nosotros cómo son aprovechados en El círculo de cal.

1. Contraposición melodramática, que en una obra didáctica es el conflicto de toda una corriente ideológica frente a otra diferente, tal y como se ilustra con la protagonista Grusha, proletaria (sirvienta) carente de los mínimos recursos para subsistir ella y para salvar a Michel, frente a toda una sociedad antagonista de ultraderecha que es individualista, egoísta, vanidosa, avara y violenta (políticos, militares, profesionistas corruptos y esposas interesadas). Para enfatizar esta oposición de valores, los personajes son simbólicos y de apariencia simple (Grusha es humilde y generosa, mientras que Natela, la esposa del gobernador, es rica y egoísta). "El teatro épico no combate las emociones, sino que las examina, y no vacila en provocarlas." (Brecht, cit. en Santana Ramos, p. 18.) En otras palabras, Brecht sí manipula al espectador con un despliegue de personajes "buenos" contra "malos”. En El círculo montado en México, esta separación se nota enfatizada por las máscaras de los personajes (más grotescas para los “malos”) y en sus voces (Grusha y Simón tienen timbres más dulces que todos los demás).

2. Distanciamiento acentuado (Verfremdung), que es el elemento técnico característico del drama didáctico, utilizando para lograrlo todos los métodos posibles de la historia del teatro: máscaras que reafirman al personaje en su grupo social (en El círculo de cal que vimos los altos funcionarios llevan elegantes sombreros, los médicos usan botarga y anteojos de erudito, y mientras, los soldados exhiben grotescas cicatrices y los pordioseros pelucas desaliñadas), coros cantados o declamados (los actores de la CíaNT hacen ambos armoniosamente), narradores (que sintetizan y estilizan el horror de la guerra en la que se enmarca este relato), elementos de juicio (presidido en nuestra obra por un juez improvisado e ignorante, pero muy intuitivo, que es Azdak) y métodos modernos de dirección (patente en la decisión de Luis de Tavira de entrenar a los actores ex profeso para esta puesta en escena en el gesto corporal y la voz, en la disposición de una escenografía de colores llamativos que se mueve para cada cuadro, en el encargo de música viva original de ritmos oscuros pero palpitantes, y en las coreografías).

3. El espectáculo, que pretende motivar al público a tomar el partido al que se le induce. Nuestra obra tiene una escenografía y coreografías que ya por sí mismas capturan la atención del espectador (como el juego escénico del caudaloso río en medio de la tormenta). La claridad del relato es asegurada por las voces, gritos y canciones del coro (que, como alter-egos de los personajes, ponen en palabras poéticas sus situaciones y dilemas). Los 
números musicales son divertidos (o sublimes, como el bautizo de Misha). El elemento más importante del espectáculo es, desde luego, el actor.

Ahora estudiaremos cómo es que estas bases estructurales son aprovechadas por sus ejecutantes, los actores, en la construcción de un espectáculo significativo y provocador.

\section{Un actor "épico"}

$\mathrm{Si}$, como todos sabemos, en este actor (el que se para en el escenario) concurren y desde el actor se proyectan todos los elementos de la representación teatral, cabe entonces atender y estudiar su participación en El círculo de cal y en todo el Teatro Épico. ¿Qué clase de actores son o deberían ser?

Es bueno cuestionarse si realmente un artista puede volverse un agente de transformación social. Ahora, en nuestro siglo XXI, se habla de "artivismo" (con "r"). La cuestión más profunda quizá sea qué tanto puede la estética fundirse, sin confundirse, con la política. Casos ejemplares (para ilustrar posibles "inconveniencias"): Un actor se siente tan comprometido con una causa que entonces se hace candidato a diputado, o gobernador, o presidente de su país; otro: un político se siente tan sensibilizado por el arte que quiere, sin dejar su cargo público y aun aprovechándolo, grabar un disco musical; uno más: los políticos que se valen de las manifestaciones artísticas como medios de publicidad.

Para concentrarnos en el caso específico del artista escénico participante de la puesta en escena de nuestro estudio, acotemos un marco, por principio, cultural. Los siguientes párrafos abundan en la búsqueda "científica" de Brecht por configurar un ejecutante que no se confundiera al hacer su trabajo en las tablas, y que, llegado el momento, realmente pudiera incidir, desde los límites de la creación teatral, en la evolución de su comunidad.

Es interesante hacer notar que el contexto histórico de escritura y montaje de El círculo de tiza caucasiano (la versión original) coincide con los tiempos de debate de las potencias ganadoras de la segunda posguerra en torno al nuevo reparto del mundo, de manera análoga a como al final de la obra se lleva a cabo el juicio sobre la patria potestad del inocente Misha. Es inevitable pensar que, en su última tesis teatral, Bertolt Brecht se preocupaba por la falta de lazos solidarios en la humanidad.

Recordemos también que Erwin Piscator y Bertolt Brecht crearon la estética del Teatro Épico (Episches Theater), luego llamado Crítico-Dialéctico por Brecht, como una respuesta artística ante los absurdos de la injusticia social en general, y de la guerra en particular, una teatralidad que despertaría en el espectador la capacidad de razonar sobre su realidad y de tomar decisiones revolucionarias. Se trataría entonces de una teatralidad que requeriría de una actoralidad particular donde el intérprete debe ser, además de un actor-artista, un actor-político.

Este actor habitaría entonces un teatro político. El Teatro Épico era expresamente ese modelo de teatro político. Un teatro político deja de ser un fin estético en sí mismo para convertirse en un medio de comunicación que propicie cambios de pensar y de actuar en el individuo, de modo que se aleje de los errores cometidos en un proyecto que debe llevarlo a la mejor realización de su esencial humanidad. No es difícil deducir que lo que pide este teatro es un actor consciente de su participación ciudadana en su comunidad, tanto de sus aportaciones individuales, considerando sus actos personales y sus consecuencias, como de las implicacio- 
nes de sus relaciones con los demás. Ahora trataremos de desmenuzar de manera comprensible esta actoralidad política, y de valorar así el reto y los alcances que enfrentaron nuestros propios actores con El círculo de cal.

El denominado Teatro Épico "se interesa principalmente en el comportamiento recíproco de los hombres en lo que tiene de social e históricamente significativo, o sea, en lo típico. En las escenas que presenta los hombres se comportan de manera que las leyes sociales a las que están sometidos sean visibles." (Brecht, citado en Castri 108), de donde se deduce que "en Brecht la dialéctica materialista, reconducida a su acaecer y verificándose dentro de los comportamientos y relaciones intersubjetivas del hombre, se expresa a través del actor." (Castri 110.) Massimo Castri observa que los objetivos y la principal línea de investigación de Brecht consiste en "hacer del teatro un instrumento que participa activamente en el esfuerzo general de transformación de la realidad." (Castri 105.)

En este punto, es claro que la demanda hacia el actor es la de un profundo compromiso personal para ser el agente activo de un proyecto social. También podemos inferir las primeras limitaciones de esta ambición desde nuestra perspectiva neo-secular. La primera limitación que vemos nosotros es que el teatro ha dejado de tener la influencia que tuvo en el público desde el siglo XVII y hasta el XIX. Quizá las últimas puestas en escena con el impacto de un motor social fueron precisamente las de Brecht a mediados del Siglo XX. La prensa, el cine, la radio, la TV y más recientemente los celulares y las redes sociales lo han dejado rezagado en sus alcances, si bien gobiernos y empresarios nunca han dejado de temerle (recordemos los casos de Augusto Boal ${ }^{1}$ y el mismo De Tavira ${ }^{2}$ en los años 70 y 80 del siglo XX). La segunda limitación del actor político es una decepción generalizada entre las nuevas generaciones por las grandes utopías ideológicas, especialmente los socialismos clásicos. Hoy los mass media fácilmente tachan como "populistas" tanto a corporaciones políticas de izquierda como de derecha dependiendo más de sus estrategias de mercadeo que de sus verdaderos programas. El alcance limitado de público y el pesimismo político son pues las condiciones objetivas que hoy la Historia contrapone a la Utopía social en la que Brecht creyó. Revisemos cómo Brecht enfoca en su momento histórico su fe en el arte como herramienta política.

Como militante marxista que es, Brecht apuesta por un teatro de la era científica, en el cual el arte se someta como instrumento de un proceso político. Pero no lo hace tan a pie juntillas como mero pregonero de las propuestas del socialismo, sino con un sentido crítico y creativo, es decir, verdaderamente revolucionario. "Brecht lleva así a cabo un alejamiento de y desde el marxismo clásico para poder recuperarlo después a través de una serie de obstáculos de un modo renovado y crítico." (Castri, p. 106) Dicho de otra manera, en su estudio hondo de la teoría marxista, Brecht descubre las potencialidades estéticas de un humanismo latente: "Brecht exalta la naturaleza dialéctica, el historicismo concreto y su carácter de teoría crítica de la sociedad capitalista y no le escapa su esencia profunda de neo-humanismo: su capacidad de 'explicar' al hombre y sus finalidades humanas." (Castri, p. 108)

Ahora bien, no se conforma con reflejar los grandes contextos socio-económicos que caracterizan a la crítica materialista, sino que busca su origen y sus consecuencias en el indivi-

1 Con la estética del Teatro del Oprimido de Boal, el teatro en Brasil pasó a ser un instrumento de lucha explícita para la transformación social, lo cual eventualmente le valió la cárcel y la tortura en febrero de 1971, y el exilio en mayo de ese mismo año.

2 Por su montaje de "Esperando al zurdo" de Odets, De Tavira pisó la cárcel en 1974, y su "Martirio de Morelos" de Leñero padeció censura en 1983 (sólo por poner dos ejemplos). 
duo común: "Brecht hunde la visión histórico-materialista en la trama de los comportamientos típicos e individuales" (Castri 108) y "Quiere que las fuerzas históricas en la escena sean realizadas simple y oscuramente como fondo." (Castri p. 108), es decir, "no sólo como un teatro que se hace portavoz de ciertos contenidos políticos, sino también un instrumento de transformación de las estructuras de comportamiento, cognoscitivas y emotivas del individuo." (Castri p. 109) El elenco mexicano hace su propia interpretación de esta perspectiva, apoyándose en la evolución dialéctica del Teatro Épico para comprender los problemas y buscar la anhelada transformación desde una reconciliación social.

Brecht sustituye progresivamente la noción de teatro épico por la de teatro dialéctico. [...] Si nos muestra el pasado y aun "el mundo tal como anda", ya no es para que lo rechacemos en bloque, sino para que lo comprendamos. [...] El mundo es abierto. Entre la Historia y la Utopía se realiza un movimiento incesante, se esboza una reconciliación. (Bernard Dort en "Programa de mano" de El círculo de cal.)

Ejemplo de la posibilidad de esta transformación ética del individuo mediante una "reconciliación" dialéctica (o dialógica) entre la Historia y la Utopía es la conmovedora escena, mitad actuada, mitad narrada, cuando en la obra comienza la guerra y todos escapan, olvidando incluso al pequeño Misha, y cuando entonces Grusha, a punto también de huir, toma la decisión más importante de su vida...

Cuando estaba así entre puerta y portón, oyó

o creyó oír una débil llamada; la llamaba

el niño, no con lloriqueos sino de forma muy clara

o así le pareció: "Mujer -le decía-, ayúdame".

Y continuó, sin lloriqueos sino hablando muy claramente:

“¿Sabes, mujer? Quien no atiende un grito de auxilio

y pasa, con oídos sordos, nunca más

oirá la débil llamada del ser amado ni

al amanecer el mirlo ni el suspiro de contento

del vendimiador al Ángelus".

Al oír eso

ella volvió, para mirar

otra vez al niño. Sólo para quedarse con él

unos minutos, sólo hasta que otro llegara,

su madre tal vez, o quien fuera.

Sólo antes de marcharse,

porque el peligro era demasiado grande y la ciudad estaba llena

de fuego y desolación.

¡Terrible es la tentación de la bondad!

Mucho tiempo se sentó junto al niño

hasta que llegó el ocaso, hasta que llegó la noche, hasta que llegó la aurora. Demasiado tiempo estuvo,

demasiado tiempo miró

su respiración tranquila, sus puñitos.

Al amanecer la tentación fue demasiado grande

y se levantó, se inclinó y, suspirando, cogió al niño

y se lo llevó.

(Brecht. Teatro completo, p. 1485) 
Es muy interesante cómo en una teatralidad que pretende privilegiar la reflexión y la crítica por encima del patetismo del drama convencional, aparece un momento tan emotivo. Aquí Grusha pone en diálogo sus emociones y opta por reconciliarse con un representante inocente de la clase social que la ha tenido oprimida, que es Misha, el hijo del gobernador "sanguijuela" (que es como lo denomina Brecht). En su Teatro Épic-Dialéctico, Brecht sugiere así cómo el sucumbir ante la "tentación de la bondad" hará posible realizar la Utopía aun en medio de las condiciones objetivas imposibles, paradójicas, de la Historia. No es extraño que el teatro, para Brecht, sea el lugar de las contradicciones: "El teatro es lugar de las contradicciones históricas cual se revelan en el interior de la trama de los comportamientos humanos sociales e individuales, desde el momento en que dichos comportamientos dejan de analizarse de modo psicológico o idealista y se analizan según la metodología del materialismo histórico." (Castri, p. 110) Para tener éxito en la indagación de este teatro humanista, Brecht es consciente de la necesidad de una renovación del actor.

Brecht dedica una mayor atención a los instrumentos humanos del teatro, al problema de la renovación del actor y a la invención de una recitación que constituya por ella misma un instrumento de conocimiento y de comunicación marxista (Castri, p. 109), [porque] en Brecht la dialéctica materialista, reconducida a su acaecer y verificándose dentro de los comportamientos y relaciones intersubjetivas del hombre, se expresa a través del actor. (Castri p. 110)

Para esta renovación, Brecht parte de la idea de que la identificación del actor con el personaje es imposible (innecesaria y contradictoria), con respecto a los fines que persigue su nueva teatralidad, lo cual le lleva a plantearse, indica Castri, el problema de la recitación.

Se pide al actor no adherirse sentimentalmente al personaje, pero al mismo tiempo estar animado por una fuerte pasión ética y gnoseológica; de este modo su recitar "distanciado" [hablaremos del distanciamiento brechtiano más adelante] le da una capacidad de aislar e iluminar las fuerzas externas en acción distinta de la actitud del actor que se ha fundido con el propio personaje, pero también diferente del actor que se distancia de cualquier cosa en la que no está implicado. Además, el actor debe ser consciente de las elecciones totales del espectáculo, de la globalidad de la comunicación puesta en movimiento, en otros términos, debe ser lúcidamente consciente de elaborar signos (que deben ser leídos activamente por el público) dentro de un complejo sistema de signos. (Castri p. 113)

Por esa razón, Brecht se da a la tarea de desarrollar una actoralidad distinta del realismo-naturalismo típicos del teatro burgués, la cual materializa a partir de un lenguaje gestual.

Lenguaje gestual es un lenguaje en el que los signos están estructurados de tal modo que "toman posición" en relación con los otros signos y con el contenido lingüístico; en el que cada signo constituye un "gesto que toma posición" y se asegura un espacio de clarificación en relación con los otros signos (Castri, p. 114)

¿Cómo podría sostenerse este lenguaje en el siglo XXI? Hasta el momento las teorías brechtianas nos han permitido imaginar a un actor "ideal" para sus obras "épicas", "didácticas", pero el verdadero reto es ver a un grupo de personas compartir estas ideas y llevarlas a la práctica de alguna manera concreta.

El apartado que a continuación presentamos muestra cómo es que un director de escena, docente, dramaturgo él mismo y pensador del teatro como Luis de Tavira, aterrizó su 
experiencia y su amor por las ideas y las obras de Bertholt Brecht para contagiar a su elenco de la Compañía Nacional de Teatro y ofrecer, en las condiciones sociales del México de la segunda década del siglo XXI, un espectáculo que conmoviera y que moviera a la gente.

\section{Un actor "dialéctico"}

Arriba hablábamos de sostener un lenguaje esencialmente gestual. En el caso de El círculo de cal, este lenguaje gestual es desarrollado a partir de un dispositivo escénico neo-expresionista, basado en el uso de máscaras y de una expresión corporal extra-cotidiana. Veremos cómo esta expresividad facilitó un basamento para, paso a paso, edificar el discurso de Brecht. Nos explica la actriz Ana Ligia García:

El trabajo con la máscara permite al espectador descubrir otras posibilidades de imaginación, de juego, y el trabajo con la máscara toca al espectador otras fibras. La máscara no oculta, ella revela. Actor y espectador viven la historia que las máscaras revelan... El trabajo con la máscara exige del actor la sabiduría para conquistar la máscara, es ella la que manda el trabajo de expresión corporal y vocal, y es tan variable como actores hay en el planeta. El realismo en este sentido está un poco más acotado... Me apasiona mi trabajo y me siento afortunada de poder acceder al mundo del trabajo con la máscara. Descubrí otros registros corporales y vocales que me ayudarán en la futura creación de mis personajes. (Entrevistas. Noviembre de 2017)

Así, “Brecht llega a un teatro 'dialéctico' en el que los signos están en una relación de violenta iluminación recíproca, como la antítesis ilumina a la tesis y viceversa, e impulsan a la urgencia de una síntesis." (Castri, p. 114) Esta confrontación dialéctica, que rompe con la identificación convencional actor/personaje y con el proceso de empatía espectador/espectáculo es definida estéticamente como un distanciamiento (Verfremdung). Cabe explicarlo:

La finalidad de esta técnica del efecto distanciador consistía en procurar al espectador una unidad analítica y crítica frente al proceso representado. Los medios eran artísticos. [.....] La premisa para conseguir el efecto distanciador es que el actor dé a aquello que quiere mostrar el gesto claro del enseñar. La idea de la cuarta pared ficticia que separa el escenario del público, produciendo la ilusión de que lo que ocurre sobre el escenario tiene lugar en la realidad, sin público, naturalmente ha de ser abandonada. En principio el actor, en estas circunstancias, podrá dirigirse directamente al público. (Brecht, Escritos sobre teatro, pp. 131-2)

Romper la cuarta pared era revolucionario para los tiempos de Brecht. Hoy no es difícil asimilar desde el patio de butacas ese rompimiento como un recurso escénico más. Misha Arias de la Cantolla es un actor al que, apenas ingresando a la CíaNT, le tocó vivir el proceso completo de montaje de El círculo de cal, y nos dice:

Estos "comentarios" hacia el público, ... el rompimiento de la cuarta pared, ... el "guiño" del personaje... comentando, mostrando su opinión, es algo significativo de este trabajo [el montaje en cuestión]... Otra de las cosas significantes con respecto a El círculo de cal es cómo el personaje "traduce" lo que le sucede en el cuerpo, ... cómo el llanto se manifiesta en TODO el cuerpo... El hecho [además] de que los actores tengan máscaras provoca [al principio] una distancia con el público, pero, conforme va pasando la historia, se va adentrando en la convención y se olvida de ello. (Entrevistas. Noviembre de 2017) 
Como recurso escénico, el distanciamiento ha demostrado facilitar al espectador la comprensión de las situaciones escénicas como problemas de la realidad del mundo. Nos confirma la actriz Paulina Treviño:

Con la actuación de máscara épica en tono de cómic, el público siente que la cuarta pared es muy delgada, siente que los personajes saben que están siendo observados por él, y eso le da permiso de hacerse presente, de expresar su sentir en la sucesión de los eventos... Este "acercamiento" de los personajes gracias a la máscara produce un "distanciamiento" personal en los individuos del público, que permite que observen las situaciones desde fuera y entiendan algo acerca de la realidad del mundo. (Entrevistas. Noviembre de 2017)

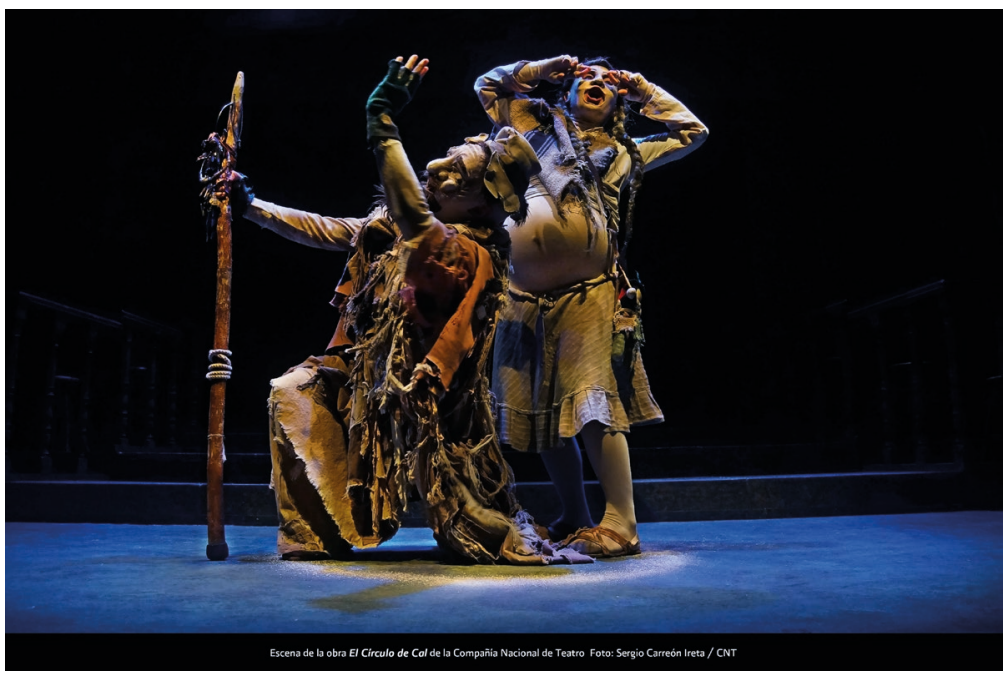

Recordemos que entender esa realidad es un paso importante para acceder eventualmente a transformarla. Si pensamos, desde nuestra actualidad, qué otras tareas sociales podría tener el actor, además de divertir al público, acaso alguna sería ésta: ayudar a comprender el mundo. Explorar esto llevó a Brecht a trazar una semiología teatral donde la participación del intérprete es muy precisa. La interpretación actoral es revolucionada por Brecht en los siguientes términos: "El actor no se permite en el escenario llegar a la transformación total en el personaje que representa. No es Lear, Harpagón, Schwejk, etc; sino que muestra a estas personas." (Brecht, Escritos sobre teatro, p. 134)

Esto no quiere decir que no hubiera un trabajo artístico de construcción de un personaje, sino que esa construcción requeriría un límite, y éste es evitar la enajenación del actor. Brecht asegura así la colaboración de un actor consiente y crítico. El actor es, pues, reconceptualizado: "[Este actor...] Dice sus frases [las de los personajes] con la mayor verdad posible, presenta sus comportamientos lo mejor que le permita su conocimiento del ser humano, pero no intenta convencerse a sí mismo (y a otros) de que se ha transformado totalmente en ellos." (Brecht, Escritos sobre teatro, p. 134)

El propósito de este distanciamiento persona/personaje es exponer la realidad de forma analítica, crítica, y, consecuentemente, transformadora. En la puesta de El círculo estudiada, el público todo el tiempo es consciente de la teatralidad de lo que ve gracias a las máscaras, pero también a los gestos. Ahora nos comparte su experiencia como actor Carlos Orozco Plascencia: 
La particularidad del estilo de actuación en El círculo de cal es lo grandilocuente de la forma. No hay lugar para el medio tono, el estilo general del montaje exige un alto voltaje energético permanente que no decae nunca, una expresividad corporal y vocal magnificada siempre. Ahora, dentro de esa forma tan estilizada, hay que encontrar la verdad en el personaje, la verdad de sus sentimientos, pensamientos, deseos, emociones, convicciones... Me parece que el público se conecta profundamente con la estética del montaje [el distanciamiento]. Eso me pasó a mí [que soy actor] cuando vi el montaje por primera vez como espectador. Entré de inmediato a la convención de este mundo que plantea la obra, ya que todos los elementos tienen consistencia y coherencia entre sí. Me parecía como un teatro guiñol gigante y maravilloso... El tema y el mensaje de la obra me parecen de lo más importante que hay que decir: hablar de la bondad, de la esperanza. (Entrevistas. Noviembre de 2017)

¿Cómo puede la estética del distanciamiento (en el caso comentado basado en máscaras y gestos grandilocuentes) detonar la pretendida transformación social? El distanciamiento (Verfremdung) determina varias implicaciones, entre las que sobresale la activación del espectador:

Mientras el lenguaje teatral [llamado realista] en el que domina la tautología y en el que los signos se intensifican recíprocamente, alcanzando una dimensión hipnótica, arrastra consigo al espectador a través de una acumulación de tensión, sin dejarle ninguna libertad de juicio crítico; en el lenguaje teatral [épico o brechtiano] en el que domina el carácter gestual de los signos, colocándose en relación recíproca de "alienación", dejan un espacio interior en el que se recupera el momento de libertad, de juicio y de intervención activa del espectador. (Castri, p. 114-5)

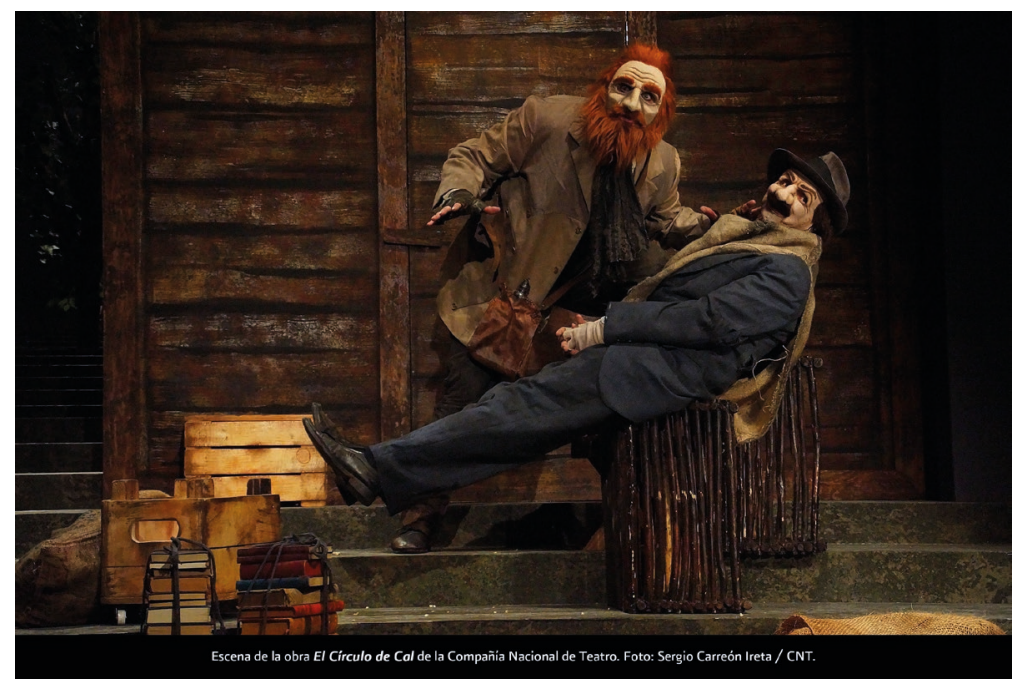

El teatro real-naturalista (no brechtiano) es tautológico en tanto que reitera los elementos significantes sobre sí mismos ("yo soy Fulano", "estamos en Francia”, "ésta es una espada", "muerto soy", etc.), confirmando los valores de la realidad, es decir, del mundo como lo conocemos, haciéndonos aceptar su idiosincrasia estética, socio-económica y política. Hace del espectáculo, por lo tanto, un evento contemplativo, y mantiene al espectador como un elemento pasivo en su contexto social. En cambio, el teatro épico (brechtiano) es crítico en el sentido de que se distancia de los objetos significantes de la realidad (que, desde luego, no pretende imitar) para poner en crisis el mundo en que vivimos, propiciando la actividad racio- 
nal y política del espectador. Por eso, Brecht pretende el "derribo del uso tautológico de los elementos de los que se compone la recitación.” (Castri, p. 129)

El distanciamiento, claramente anti-naturalista, tiene una necesidad: "El distanciamiento en efecto debe poner en movimiento una dialéctica entre cotidiano y sorprendente, y el primer elemento no puede desaparecer, o sería vano cualquier intento de remitirse a la praxis, a una real voluntad de modificación." (Castri, p. 129) Es decir, que el espectador debe salir de la sala teatral con la convicción y el impulso de transformar su cotidianeidad. Por esto, podemos decir que una de las funciones del teatro en la epicidad brechtiana es combatir la pasividad del espectador, pues mientras en el teatro tradicional se nos provoca satisfacción y éxtasis, impidiendo así cualquier relación con la praxis en el mundo real, es decir, impidiendo tensiones cognoscitivas, procesos de transformación de los propios comportamientos y de las propias estructuras psíquicas, además de la acción política inmediata; en cambio, en el teatro épico...

La eficacia política del teatro en particular consiste no tanto en el volverse capaz de comunicar nuevos contenidos y datos inmediatamente practicables cuanto en ser capaz de inducir en el espectador nuevos modos de pensamiento e instrumentos de análisis, nuevas actitudes mentales y de comportamiento, ocupándose en una transformación del individuo (Castri p. 120)

El Teatro Épico-Dialéctico propicia el desarrollo de actitudes que vean por el interés común, por encima del interés personal. Es importante hacer notar que éste no ha dejado de ser el perfil ideal que los pueblos buscan en sus gobernantes, de ahí la importancia de mecanismos de educación de ciudadanos solidarios, entre ellos los artistas y los políticos, y de ahí la vigencia de un teatro que siga apostando por la Utopía, a pesar de que las condiciones objetivas acusen su imposibilidad. Desde luego, una poética teatral con estos objetivos necesita su propia unidad, la cual el Teatro Épico-Dialéctico logra partiendo de sus propios elementos constitutivos.

En el teatro brechtiano encontramos unidad de platea/escenario, pero no una unidad que se crea mágicamente dentro del teatro, sino una unidad de intereses culturales y sociales, de voluntad cognoscitiva y política, que existe a priori respecto al espectáculo y es trasladada desde el exterior "real" al interior del acontecimiento teatral para después proyectarse de nuevo en la praxis real. El interés común sustituye al mecanismo de la empatía [identificación sentimental con el personaje en el teatro tradicional] (Castri p. 123)

El director Luis De Tavira no dejó de buscar esta unidad basada en el interés común. Para ello llevó el conflicto por el territorio y por el niño Misha de El círculo de cal a la provincia de Michoacán, en México, donde diversos grupos pelean por el derecho a talar o a conservar los bosques maderables. Esto se plantea en una introducción video-proyectada donde en medio de una acalorada discusión entre pobladores michoacanos se presentan un par de actores de la CíaNT para invitarlos a ver su función (lo cual reelabora una de las primeras escenas de la versión textual definitiva de El círculo de tiza caucasiano). Así logró mantener las mismas preguntas que se hace Brecht: “¿De quién son los niños, de quién es la tierra?” en el siglo XXI y en territorio mexicano.

Brecht no limita su indagación por la unidad platea/escenario al plano del ideal, sino que lo aterriza en un procedimiento de valor no sólo estético, sino científico. El procedimiento por el cual estas ideas funcionan en un espectáculo tiene dos fases: 
a.) Por una parte, asume y presenta la realidad en cuanto "modificable", porque está animada en su interior de una tensión dialéctica que la impulsa a transformarse (tendencia objetiva y posibilidad de cambio), y, al mismo tiempo, comunica la necesidad del cambio, mostrando y enraizando las contradicciones socioeconómicas en las monstruosidades y en las deformaciones que provocan en el hombre (momento subjetivo y exigencia ética del cambio.)

b.) Por otra parte, tienda a inducir al espectador con su mismo modo de funcionamiento (evitando la identificación en la relación espectáculo/realidad, la identificación y la catarsis en la relación espectáculo/espectador, y estimulando en el público una actividad crítica y una tensión emocional al cambio), actitudes mentales y emotivas que lo hagan apto para el cambio y deseoso de cambio.

(Castri, p. 127)

En esta teatralidad, para presentar la realidad como "modificable" y motivar el deseo de cambio en el espectador se necesita también un protocolo actoral. Este protocolo consiste en:

a.) Un efecto de distanciamiento entre actor y personaje, que es el punto de partida, la plataforma mínima de cualquier recitación épica, en la que el actor "narra”, articulando los nexos, una "mimesis" del personaje.

b.) Un efecto de crítica en el que el actor ejercita, además de permanecer distanciado, una acción de análisis y corrosión sobre el personaje, actuando sobre los materiales mímicos y fónicos, todavía sustancialmente realistas de los que se compone el personaje.

c.) Un nuevo efecto de distanciamiento que vuelve "ajeno" el papel a través de una serie de invenciones mímicas y fónicas que entran con él en una relación dialéctica, recuperando una zona de fantasía y de intervención sobre los materiales dados más decididamente antinaturalista. (Cfr. Castri, p.130-1)

Distanciamiento actor/personaje, análisis crítico e intervención anti-naturalista son prácticas que sólo podría ejecutar un intérprete más comprometido con la realidad que con la ficción. En El círculo montado en México, esto lo lleva a cabo un ejecutante como Andrés Weiss de la siguiente manera:

Lo épico yo lo veo más en lo episódico del texto. Al estar compuesto de unidades [secuencias de acción sucesivas], es un reto la progresión energética de la obra: Cómo doy continuidad y hago crecer las escenas que me tocan para alimentar el todo. El trabajo de máscara añade otra complejidad. Todo se vuelve enorme y requiere de mucha precisión. Para mí cada temporada era un reto hacer crecer más a los personajes, tanto anímica como físicamente... A fin de cuentas, al ser un teatro arraigado en lo social uno representa un estereotipo y eso también hay que saber jugarlo. El foco está en lo social, en lo que representa el personaje, y no en su psicología... El montaje permitía a momentos una franca interacción con el público y está comunicación directa alimenta mucho a la máscara. Para mí, era un trabajo de enorme libertad y transformación, la máscara revela muchas cosas. Yo jugaba mucho con ellas fuera de escena para descubrir sus matices, aunque a veces espanta a dónde te pueden llevar... Hacer El círculo de cal implica planear tu día y tu semana alrededor de las funciones. Es de los trabajos más agotadores que he hecho, pero a la vez de los más placenteros. (Entrevistas. Noviembre de 2017) 


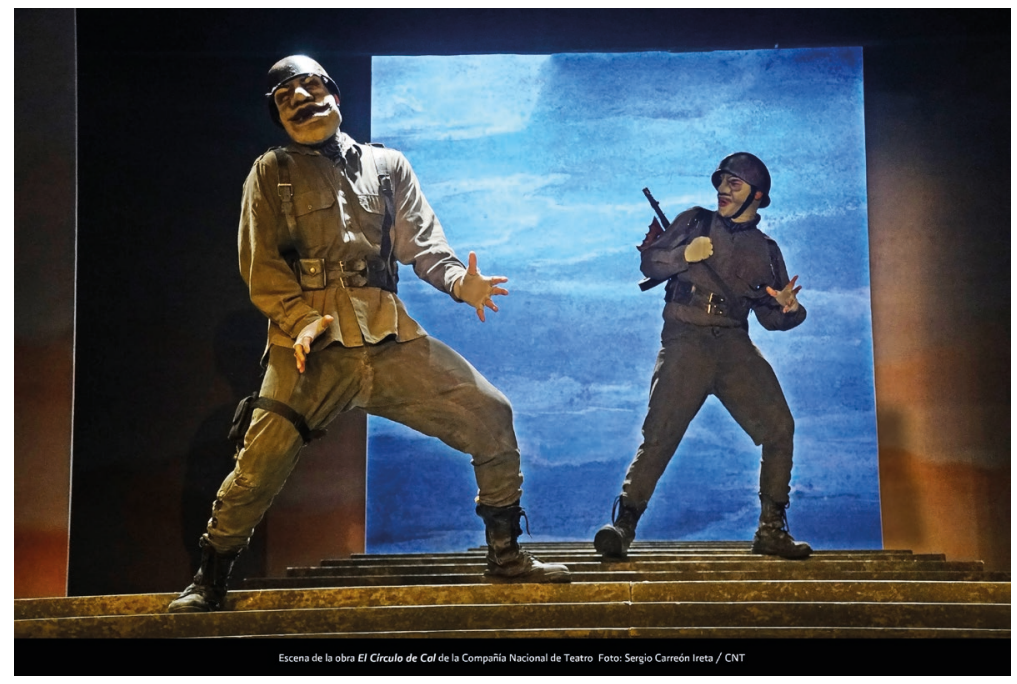

Es importante, por otro lado, reconocer que mucho del método épico de Brecht se debe a las investigaciones de Stanislavski $(2013,1992,1990)$ sobre el trabajo del actor. Brecht partía de algunos de sus postulados con el fin posterior de llegar más lejos. Castri ofrece la siguiente comparación entre los métodos de trabajo de Stanislavski y de Brecht.

Mientras Stanislavski propone el trabajo del actor como búsqueda de verdad y de realización de sí mismo, destrucción de la "máscara" cotidiana para alcanzar un núcleo de verdad profunda, y pone como implícita garantía de la licitud de este modelo de trabajo la asunción del individuo como no condicionado históricamente por una sociedad alienada, sino como portador de verdades psíquicas eternas; Brecht, en cambio, historicista y marxista, asume el punto de vista del materialismo histórico como fundamental, individualiza al hombre en su condición histórica no liberada, y, por tanto, requiere del actor el proceder a la exploración de sí mismo (y también de los otros y de sus comportamientos) y el actuar en seguida sobre los materiales recuperados a través de esta investigación: "Distanciar significa historiar... también en el caso de los personajes contemporáneos; también sus actitudes se pueden representar como contingentes, históricas, transitorias." (Castri p. 133, la cita que hace de Brecht no tiene referencia.)

Las verdades psíquicas que Stanislavski veía en el individuo como inmutables en el tiempo y a pesar de los cambios en las estructuras socio-económicas dibujan una especie de "hombre universal", mismo que constituye la base de su sistema actoral. Hay que decir que: "El hombre universal, presupuesto a priori por Stanislavski, es reintroducido por Brecht como término y fin del proceso histórico y como "presencia" que ilumina las contradicciones históricas" (Castri, p. 134), de donde entendemos que para Brecht este hombre idealizado no es el principio, sino el fin del proceso. Evidentemente, Brecht hace del teatro un medio de... "Evidenciación crítica de las contradicciones de la realidad y proyección de una realidad alternativa." (Castri, p. 134)

La intérprete Pilar Padilla comenta las diferencias entre la técnica realista desarrollada por Stanislavski y la técnica épica explorada a partir de máscaras en El círculo de cal:

Las diferencias actorales tienen que ver obviamente con la técnica de cada lenguaje, en este caso [en El círculo de cal] la máscara permite una exploración mucho más radical en la forma y en la expresividad corporal. Como se trata de un objeto inanimado, que en este caso se 
coloca no sólo en la cara sino en todo el cuerpo, la energía debe traspasar el objeto para que llegue al espectador. Como en el realismo, buscamos el contenido de esa máscara, pero el análisis no es psicológico [como con Stanislavski], sino que trata de encontrar el signo expresivo en cada situación y en cada personaje, y a partir de ahí cada actor construye su máscara. Hay reglas, como por ejemplo la hiper-proyección de las emociones, donde si el personaje ríe o llora lo hace con todo el cuerpo... Yo no estaba originalmente en el reparto, los directores no sabían que he tenido entrenamiento anterior con máscara. Rogué para estar. A Octavio Michel, el director residente, se le ocurrió que inventáramos un personaje que no existía en el montaje original para acompañar a la Maestra Rosenda Monteros en la escena de "Las Fugitivas". Fue precioso el proceso y la experiencia de integrarme a la escena. Me siento muy orgullosa de haberlo hecho. (Entrevistas. Noviembre de 2017)

También el Mtro. Óscar Narváez, experimentadísimo actor y parte de este elenco, manifiesta:

En un proceso naturalista, la interpretación está elaborada a partir de sutilezas y detalles en lo emotivo, en lo físico y en lo oral, en concordancia con el carácter y circunstancia de un personaje, para lograr un desarrollo creíble y "natural" en escena; es decir, lo que el espectador observa debe estar más cerca de lo razonablemente posible como espejo del comportamiento humano. Al enfrentarnos a un proceso actoral y estético como el de $E l$ círculo de cal, lo anteriormente expuesto adquiere una dimensión extraordinaria por virtud de la expresividad que el uso de la máscara implica. La máscara magnifica el comportamiento humano y revela, sin menoscabo de una verdad escénica, las entrañas de un personaje: la máscara de su apariencia y la anti-máscara de su realidad. Luego entonces, la máscara se convierte en una lupa que evidencia, con mayor rigor, el trabajo actoral. Encontrar el punto de equilibrio que permita sustentar la dimensión propia de un trabajo actoral naturalista y uno "épico" es el reto interpretativo que confronta las posibilidades creativas de un actor. (Entrevistas. Noviembre de 2017)

Para el actor, como se ha constatado, las exigencias son complejas. El actor es responsable de proyectar no sólo una nueva forma de teatro, sino una nueva perspectiva sobre el hombre: "En el hombre hay mucho, decimos: así, pues, podrá hacerse mucho del hombre. Así como es no debe permanecer; no basta considerarlo como es, es necesario verlo también como podría ser. No es necesario partir de él, sino hacia él. Se puede decir que no basta que yo me ponga en su puesto: debo ponerme frente a él, en representación de todos nosotros. He aquí por qué el teatro debe distanciarse de lo que muestra." (Brecht, citado sin referirse título de la fuente en Castri, p. 131)

Una gestualidad que evite que los espectadores se identifiquen con el personaje, un distanciamiento que facilite la comprensión de la situación escenificada como una problemática que puede ser modificada, la reducción de una respuesta emocional en beneficio de una actitud reflexiva, crítica y transformadora, y una proyección del hombre como podría llegar a ser, son en resumen las características del perfil actoral desarrollado en el Teatro Épico-Dialéctico por Bertolt Brecht, capaces de sostenerse más allá del aforo limitado de una sala teatral y del pesimismo ideológico que caracteriza nuestro momento histórico. De aquí que los actores, tanto para Brecht como para toda poética teatral, deben estar dispuestos a un continuo aprendizaje.

Al acercarse el cierre de este trabajo, me he atrevido a sugerir las siguientes líneas, imaginadas desde el pecho de un actor teatral... 
Este engendro que soy, agitalanzas, corazón de tigre en piel de actor, héroe mortal, enmascarado, gritón, desnudo de tanta ropa, feliz de tanto ser otros, flama fallecida llegado el amanecer, quiere ser a un tiempo belleza, bondad y verdad, y salvar al mundo con un verso, un gesto y una lágrima, pero sólo me intuyo vivo si, por ventura, por ti, llego a ser visto. ¡Qué condena bendita, maldita bendición, vivir un instante para ti, y ser amado y odiado en un otro, para luego ser olvidado! Yo sólo quiero sacudir tu corazón, sembrarte dudas, hacerte acaso sonreír. Y sólo pido a cambio el pan de esta comunión. Si acaso el mundo llega a cambiar por mi danza, mi pregón y mi canto, entonces entiérrame con flores.

Y ojalá sea para bien, para que los hombres vuelvan a ser hermanos y buenos hijos de la tierra.

\section{Conclusión}

La capacidad de aprender, des-aprender y re-aprender acaso nos permita acceder a la resiliencia que demanda el siglo XXI para sobrevivir como humanidad. Hoy la pertinencia de todas estas teorías de Brecht es defendida por directores destacados, como Luis de Tavira, director escénico de El círculo de cal. Y, claro, por los actores, que encuentran en su obra una valiosa esperanza para el ser humano: "Uno puede sentir que la obra toca el corazón del público y le aporta un poco de alivio, un poco de alegría, un poco de esperanza, un poco de luminosidad. Y es lo que más satisfacción puede darme a mí como ser humano y como actor." (Carlos Orozco Plascencia. Entrevistas. Noviembre de 2017)

Con El círculo de cal, se cuestiona y se actualiza, una vez más, la vigencia del Teatro Épico-Dialéctico de Bertholt Brecht, donde los intérpretes arriesgan todas sus capacidades para enriquecer la experiencia del espectador. Esta experiencia nos sugiere que ceder a la tentación de la bondad puede salvarnos de la destrucción. La Compañía Nacional de Teatro de México ha puesto a nuestra consideración un poema escénico que rescata el potencial del arte teatral como instrumento de transformación de la realidad del hombre, poniendo énfasis en el actor como su agente principal. 


\section{Agradecimientos}

Agradezco profundamente a Ana Ligia García, Paulina Treviño, Pilar Padilla, Andrés Weiss, Carlos Orozco Plascencia, Óscar Narváez y Misha Arias de la Cantolla, por compartir, en extraordinarias entrevistas que realicé en noviembre de 2017 , sus luminosas experiencias actorales.

\section{Referencias bibliográficas}

Brecht, Bertolt. (2004) [1933-47.] Escritos sobre teatro. Barcelona: Alba.

Brecht, Bertolt. (1989). Las visiones y los tiempos oscuros. México: UNAM.

Brecht, Bertolt. (1976). Poesía. La Habana: Instituto Cubano del Libro.

Brecht, Bertolt. (2009) (1967). Teatro completo. Madrid: Cátedra.

Castri, Massimo. (1978). Por un teatro político: Piscator, Brecht, Artaud. Madrid: Akal.

Dort, Bernard. (2013). "Programa de mano" de El círculo de cal. México: CNT.

Harmony, Olga. (2013). "El círculo de cal”, en La Jornada. Jueves 17 de enero de 2013.

Martínez Monroy, Fernando (inédita). Tesis doctoral. Madrid: Universidad Complutense.

Martínez Monroy, Fernando (2018.) Cátedra de teoría dramática. (Seminario, taller y curso.) México: Ápeiron.

Ponce, Armando. 1981. “De Tavira: Por un teatro que recupere la conciencia colectiva”, en Proceso. 19 de septiembre de 1981.

Rivera, Virgilio Ariel. 1993 (1989.) La composición dramática. México: Gaceta.

Stanislavski, Constantin. (2013). Mi vida en el arte. La Habana: Alarcos. Estudio preliminar de N. Volkov.

Stanislavski, Constantin. (1992). Creación de un personaje. México: Diana.

Stanislavski, Constantin. (1990) (1953). Un actor se prepara. México: Diana.

(C) Los autores. Este artículo es publicado por la Horizonte de la Ciencia de la Unidad de Posgrado de la Facultad de Educación de la Universidad Nacional del Centro del Perú. Este es un artículo de acceso abierto, distribuido bajo los términos de la Licencia Atribución-No Comercial 4.0 Internacional.(https://creativecommons.org/licenses/by-nc/4.o/), que permite el uso no comercial y distribución en cualquier medio, siempre que la obra original sea debidamente citada. 